\title{
Intellectual performance after presymptomatic cranial radiotherapy for leukaemia: effects of age
} and sex

\author{
D Christie, A D Leiper, J M Chessells, F Vargha-Khadem
}

\begin{abstract}
Cognitive outcome, as measured by verbal and performance IQs, was compared in 35 girls and 47 boys who were in first remission for acute lymphoblastic leukaemia. All children had received presymptomatic cranial radiotherapy and intrathecal methotrexate. The mean age at diagnosis was $4 \cdot 2$ years and the mean elapsed time from initial diagnosis to intellectual assessment was $7 \cdot 1$ years.

Results showed that children irradiated before the age of 4 years were impaired in certain aspects of non-verbal ability, as well as in measures of short term memory and attention, calculated by factor scores derived from selected subtests of the IQ test. Subtests requiring verbal and nonverbal reasoning showed the greatest impairment after early diagnosis and treatment. In addition girls were selectively impaired in verbal IQ and other aspects of verbal ability, with the degree of impairment exacerbated by early treatment. No relationship was found between degree of impairment and either time since treatment or number of methotrexate injections. It is concluded that early age at irradiation increases the risk of impaired intellectual outcome, particularly in girls. (Arch Dis Child 1995; 73: 136-140)
\end{abstract}

Keywords: leukaemia, intellectual outcome, cranial radiotherapy.

Neurosciences Unit, Institute of Child Health, University of London, and Department of Psychological Medicine, Great Ormond Street Hospital for Children NHS Trust, London D Christie

F Vargha-Khadem

Department of Haematology and Oncology, Great Ormond Street Hospital for Children NHS Trust, London A D Leiper

J M Chessells

Correspondence to: Dr D Christie, Neurosciences Unit, Institute of Child Health, The Wolfson Centre, Mecklenburgh Square, London WC1N 2AP.

Accepted 14 March 1995 suffer from late side effects of treatment. These adverse effects include growth and endocrine dysfunction, ${ }^{45}$ brain abnormalities such as calcification and white matter changes, ${ }^{67}$ and cognitive impairment, commonly manifested as lowered intelligence (IQ) and memory capacity. ${ }^{8-10}$ The brain pathology has been attributed to vascular and biochemical abnormalities resulting from both radiotherapy and chemotherapy. ${ }^{6} 1112$ This evidence has led to a reduction in the total dose of radiotherapy, increasing the number of fractionations in which the total cranial radiotherapy dose is given, and, more recently, avoidance of cranial radiotherapy in children less than 2 years of age. This young age group appears to be most vulnerable to the deleterious effects of treatment. ${ }^{13}$

The effect of age at treatment may be related to age dependent myelination rates in the developing central nervous system. The process of myelination begins during the fetal period and continues well into adulthood. However, the most dramatic changes occur during the first two years of postnatal life. As different anatomical regions (and therefore functional systems) myelinate at different times there may well be a differential response to neurotoxins as a function of age and stage of brain development, with early stages creating windows of vulnerability in various functional systems. ${ }^{14}$ The precise relationship between age at treatment and degree of specific cognitive defects, however, is still unknown.

Sex differences to adverse effects of treatment have also been reported, with females being more at risk than males. The two indices of this greater vulnerability are the frequent occurrence of severe growth failure in girls ${ }^{415}$ and an increased incidence of early puberty. ${ }^{5}$ A greater risk for females than males has also been reported in relation to cognitive outcome. ${ }^{1617}$ The evidence is still scanty as small sample sizes have often precluded the division of groups on the basis of sex.

Although there is a consensus that intellectual ability declines over time after cranial radiotherapy and central nervous system chemotherapy, ${ }^{1018}$ most studies base their conclusions on IQs that have been estimated from a selected sample of subtests. ${ }^{19} 20$ As each subtest assesses a different facet of intellectual ability, it is difficult to ascertain, on the basis of estimated IQ scores, which aspects of intelligence are most vulnerable to delayed effects of treatment. The purpose of this study was to examine a large group of children who are long term survivors of acute lymphoblastic leukaemia (ALL) and compare in detail their full intellectual profiles as a function of age at treatment, time since treatment, and sex.

\section{Subjects and methods}

Eighty two children ( 35 girls, 47 boys) who had ALL diagnosed between 1980 and 1986 agreed to participate in the study. We used the age of 4 years to divide the children into two treatment groups for the following reasons. Firstly, in a meta-analysis of studies that reported on age related effects the most pronounced cognitive deficits were found when treatment was administered around 4 years of 
Table 1 Summary of clinical details showing age at diagnosis, age at testing, and elapsed time from diagnosis to assessment in years; details of central nervous system directed treatment are also given

\begin{tabular}{|c|c|c|c|c|}
\hline & \multicolumn{4}{|c|}{ Age at cranial radiotherapy (years) } \\
\hline & \multicolumn{2}{|l|}{ Girls } & \multicolumn{2}{|l|}{ Boys } \\
\hline & $<4(n=20)$ & $\geqslant 4(n=15)$ & $<4(n=26)$ & $\geqslant 4(n=21)$ \\
\hline $\begin{array}{l}\text { Mean age at diagnosis } \\
\text { Range } \\
\text { Mean age at testing } \\
\text { Range } \\
\text { Mean time since diagnosis } \\
\text { Range } \\
\text { Cranial radiotherapy dose in cGy } \\
\text { (No of children) }\end{array}$ & $\begin{array}{l}2 \cdot 6 \\
1 \cdot 0-3 \cdot 8 \\
9 \cdot 6 \\
6 \cdot 0-13 \cdot 5 \\
7 \cdot 3 \\
3 \cdot 4-10 \cdot 2 \\
1800(20)\end{array}$ & $\begin{array}{c}5 \cdot 8 \\
4 \cdot 4-10 \cdot 3 \\
13 \cdot 3 \\
10 \cdot 9-17 \cdot 8 \\
6 \cdot 9 \\
4 \cdot 1-8 \cdot 5 \\
1800(14) \\
2400(1)\end{array}$ & $\begin{array}{c}2 \cdot 3 \\
1 \cdot 1-3 \cdot 9 \\
9 \cdot 8 \\
5 \cdot 8-13 \cdot 9 \\
7 \cdot 6 \\
4 \cdot 4-12 \cdot 2 \\
1500(1) \\
1800(21) \\
2400(4)\end{array}$ & $\begin{array}{c}6 \cdot 8 \\
4 \cdot 1-11 \cdot 9 \\
13 \cdot 5 \\
9 \cdot 5-19 \cdot 1 \\
6 \cdot 8 \\
4 \cdot 2-8 \cdot 8 \\
1760(1) \\
1800(20)\end{array}$ \\
\hline $\begin{array}{l}\text { No of methotrexate injections } \\
\text { (No of children) }\end{array}$ & $\begin{aligned} & 6(10) \\
& 7(2) \\
& 8(3) \\
& \geqslant 10(5)\end{aligned}$ & $\begin{array}{l}2(1) \\
6(7) \\
7(5) \\
8(2)\end{array}$ & $\begin{array}{r}4(1) \\
6(7) \\
7(5) \\
8(4) \\
\geqslant 9(9)\end{array}$ & $\begin{array}{l}6(3) \\
7(6) \\
8(12)\end{array}$ \\
\hline Mean & $8 \cdot 5$ & $6 \cdot 3$ & $9 \cdot 04$ & $7 \cdot 4$ \\
\hline
\end{tabular}

age. ${ }^{18}$ Secondly, in the present study the mean age at starting prophylactic central nervous system treatment (that is, intrathecal methotrexate injections administered as part of induction) was $4 \cdot 2$ years (range $1 \cdot 0-11 \cdot 9$ ). Twenty girls and 26 boys were diagnosed and treated before 4 years of age, 15 girls and 21 boys received treatment at 4 years or later. The mean period in first remission was $7 \cdot 1$ years (range $3 \cdot 4-12 \cdot 2$ ). Children were treated with either PLOD, ${ }^{21}$ UKALLX pilot, ${ }^{22}$ or UKALLX protocols. ${ }^{3}$ These protocols consisted of a four drug induction phase, one or two consolidation blocks, continuing (maintenance) treatment for two years, and central nervous system directed treatment to prevent overt meningeal infiltration. Five children received $2400 \mathrm{cGy}$ in 15 fractions (over 19 days), whereas the remaining 77 were treated with $1800 \mathrm{cGy}$ in 10 fractions (over 14 days). In addition an average of six to eight injections of intrathecal methotrexate were administered. Children diagnosed before the age of 2 years did not undergo cranial irradiation until their second birthday, and consequently received additional intrathecal methotrexate injections. ${ }^{13}$ Boys received on average one more methotrexate injection than girls. This sex difference for the children treated at 4 years or later was significantly different in a $\chi^{2}$ comparison; however, an overall analysis of variance of mean methotrexate injections did not find a difference for either age or sex. Table 1 summarises the diagnostic and treatment details of the four ALL groups.

\section{PROCEDURES}

The age appropriate Wechsler intelligence scales were administered to evaluate intellectual ability. Seventy five children received the Wechsler intelligence scale for children revised (WISC-R), ${ }^{23}$ six the Wechsler adult intelligence scale - revised (WAIS-R), ${ }^{24}$ and one the Wechsler preschool and primary scale of intelligence - revised (WPPSI-R). ${ }^{25}$ Verbal and performance IQs were calculated on the basis of the complete set of 12 subtests. Five subtests are used to calculate each of the verbal and performance scales. For those children who completed the WISC-R or WAIS-R, three factor based index scores were calculated in addition to the IQ scores $^{26}$ : verbal comprehension, perceptual organisation, and freedom from distractibility. The Appendix gives a brief description of each factor and subtests.

The IQ and the factor based measures were expressed as standard scores with a mean (SD) of 100 (15) whereas the subtest scores were expressed as scaled scores (range 1-19; mean (SD) 10 (3)).

Effects of treatment on intellectual outcome were examined using three types of analyses. First, $t$ tests were used to compare the IQs of the ALL group with the hypothetical mean of the normal population. Population norms on the Wechsler scales have increased gradually over time. To compensate for this inflation in scores, the IQs of the ALL group were compared with the hypothetical mean of 105 rather than 100 , that is, addition of 0.3 of an IQ point for each year since standardisation. ${ }^{27-29}$ As corrections for individual subtests are not currently available, $t$ tests were carried out on the unadjusted scaled scores of each subtest, comparing each mean with the hypothetical mean of 10 . This provides a more conservative estimate of impairment on the subtests than on the overall scales.

Secondly, a two by two multivariate analysis of variance (MANOVA) compared the IQs, the factor based index scores, and the scaled subtest scores of the ALL group according to sex and age at treatment ( $<$ or $\geqslant 4$ years). The analysis was repeated with the variables of time since treatment and number of methotrexate injections treated as covariates. Finally, a series of multiple regression analyses were carried out on all measures, treating in each case the factor of age at treatment as a continuous variable. For each analysis, the variables of time since treatment and number of methotrexate injections were entered first. The variables of sex, age at treatment, and sex by age at treatment (that is, the interaction term) were added next as independent variables.

Data were analysed using the statistical package for social sciences (SPSS/PC + ).

\section{Results}

(1) $t$ TESTS

Table 2 shows the verbal IQ, performance IQ, factor scores, and subtests scores for the whole sample and the four ALL groups. Both the verbal IQ with a mean (SD) of 94.21 (11.92) and the performance IQ with a mean (SD) of 99.73 (13.88) of the ALL group were significantly lower than the hypothetical population mean of 105 (verbal IQ: $t=8 \cdot 17, \mathrm{p}<0.01$; performance IQ: $t=3.44, \mathrm{p}<0.01)$. Furthermore all three factor based index scores were significantly lower than the population mean (verbal comprehension: $t=7 \cdot 76, \mathrm{p}<0.01$; perceptual organisation: $t=3 \cdot 3, \mathrm{p}<0.01$; freedom from distractibility: $t=6 \cdot 79, \mathrm{p}<0 \cdot 01)$. When the overall mean scores of the ALL group were compared against the hypothetical population mean of 100 , verbal IQ $(t=4 \cdot 42)$, verbal comprehension $(t=3.82)$, and freedom from distractibility $(t=3.76)$ were all significant at the 0.01 level. Both performance IQ $(t=0 \cdot 18)$ and perceptual 
Table 2 Mean (SD) scaled scores for verbal and performance IQ, verbal comprehension, perceptual organisation, freedom from distractibility and individual subtests

\begin{tabular}{|c|c|c|c|c|c|c|c|c|}
\hline & \multicolumn{5}{|c|}{ Age at cranial radiotherapy (years) } & \multirow{3}{*}{$\begin{array}{l}\text { Significant } \\
\text { effect }\end{array}$} & \multirow{3}{*}{$\begin{array}{l}F \\
\text { value }\end{array}$} & \multirow{3}{*}{$\stackrel{p}{\text { Value }}$} \\
\hline & \multirow{2}{*}{$\begin{array}{l}\text { Total group } \\
4 \cdot 5(n=82)\end{array}$} & \multicolumn{2}{|l|}{ Girls } & \multicolumn{2}{|l|}{ Boys } & & & \\
\hline & & $<4(n=20)$ & $\geqslant 4(n=15)$ & $<4(n=26)$ & $\geqslant 4(n=21)$ & & & \\
\hline $\begin{array}{l}\text { Verbal IQ } \\
\text { Performance IQ }\end{array}$ & $\begin{array}{l}94 \cdot 2(11 \cdot 9)^{\star} \\
99.7(13 \cdot 9)\end{array}$ & $\begin{array}{l}86 \cdot 8(11 \cdot 1) \\
96.3(9 \cdot 6)\end{array}$ & $\begin{array}{r}96.0(11 \cdot 0) \\
105.9(13 \cdot 1)\end{array}$ & $\begin{array}{l}96.5(12.5) \\
98.8(16.3)\end{array}$ & $\begin{array}{l}97 \cdot 1(10 \cdot 3) \\
99 \cdot 8(14 \cdot 0)\end{array}$ & Gender & $4 \cdot 5$ & 0.037 \\
\hline $\begin{array}{l}\text { Verbal comprehension } \\
\text { Information } \\
\text { Similarities } \\
\text { Vocabulary } \\
\text { Comprehension }\end{array}$ & $\begin{array}{l}95 \cdot 1(11 \cdot 6) \star \\
8 \cdot 4(2 \cdot 5) \\
9 \cdot 8(2 \cdot 9) \\
9 \cdot 5(2 \cdot 6) \\
8 \cdot 9(2 \cdot 3)\end{array}$ & $\begin{array}{l}88 \cdot 4(11 \cdot 6) \\
7 \cdot 5(2 \cdot 3) \\
8 \cdot 4(3 \cdot 6) \\
8 \cdot 2(2 \cdot 5) \\
8 \cdot 0(2 \cdot 5)\end{array}$ & $\begin{aligned} 97 \cdot 2(9 \cdot 7) \\
8 \cdot 8(2 \cdot 2) \\
10 \cdot 9(2 \cdot 1) \\
9 \cdot 5(2 \cdot 1) \\
8 \cdot 8(1 \cdot 5)\end{aligned}$ & $\begin{array}{c}97 \cdot 0(11 \cdot 9) \\
8 \cdot 9(2 \cdot 7) \\
9 \cdot 5(2 \cdot 2) \\
10 \cdot 2(2 \cdot 9) \\
9 \cdot 2(2 \cdot 5)\end{array}$ & $\begin{array}{l}97 \cdot 8(10 \cdot 7) \\
8 \cdot 2(2 \cdot 5) \\
10 \cdot 9(2 \cdot 8) \\
9 \cdot 9(2 \cdot 5) \\
9 \cdot 6(2 \cdot 1)\end{array}$ & $\begin{array}{l}\text { Age } \\
\text { Gender } \\
\text { Gender }\end{array}$ & $\begin{array}{l}9 \cdot 9 \\
4 \cdot 4 \\
4 \cdot 2\end{array}$ & $\begin{array}{l}0.002 \\
0.040 \\
0.043\end{array}$ \\
\hline $\begin{array}{l}\text { Perceptual organisation } \\
\text { Picture completion } \\
\text { Picture arrangement } \\
\text { Block design } \\
\text { Object assembly }\end{array}$ & $\begin{array}{c}100 \cdot 4(12 \cdot 7) \\
9 \cdot 8(2 \cdot 4) \\
9 \cdot 8(2 \cdot 5) \\
10 \cdot 6(3 \cdot 0) \\
10 \cdot 2(3 \cdot 0)\end{array}$ & $\begin{array}{l}96 \cdot 7(9 \cdot 8) \\
9 \cdot 9(2 \cdot 3) \\
9 \cdot 6(2 \cdot 5) \\
9 \cdot 6(2 \cdot 4) \\
8 \cdot 8(2 \cdot 4)\end{array}$ & $\begin{array}{c}105 \cdot 7(12 \cdot 8) \\
10.0(2 \cdot 0) \\
10 \cdot 1(2 \cdot 0) \\
11.9(2 \cdot 8) \\
11.6(3 \cdot 4)\end{array}$ & $\begin{array}{l}98 \cdot 5(13 \cdot 5) \\
9 \cdot 8(2 \cdot 9) \\
9 \cdot 6(3.0) \\
10 \cdot 1(3 \cdot 4) \\
10 \cdot 2(2 \cdot 5)\end{array}$ & $\begin{array}{c}102 \cdot 3(13 \cdot 4) \\
9 \cdot 8(2 \cdot 3) \\
10 \cdot 2(2 \cdot 1) \\
11 \cdot 1(3 \cdot 0) \\
10 \cdot 4(3 \cdot 3)\end{array}$ & $\begin{array}{l}\text { Age } \\
\text { Age }\end{array}$ & $\begin{array}{l}6 \cdot 9 \\
5 \cdot 2\end{array}$ & $\begin{array}{l}0.010 \\
0.025\end{array}$ \\
\hline $\begin{array}{l}\text { Freedom from distractibility } \\
\text { Arithmetic } \\
\text { Digit span } \\
\text { Coding }\end{array}$ & $\begin{array}{l}93.8(15 \cdot 0) \star \\
8 \cdot 9(3 \cdot 0) \\
8 \cdot 8(2 \cdot 5) \\
9 \cdot 5(3 \cdot 2)\end{array}$ & $\begin{array}{c}90 \cdot 9(13 \cdot 4) \\
7 \cdot 4(2 \cdot 0) \\
8 \cdot 8(2 \cdot 3) \\
9 \cdot 6(2 \cdot 8)\end{array}$ & $\begin{array}{c}95 \cdot 4(16 \cdot 8) \\
9 \cdot 0(3 \cdot 5) \\
8 \cdot 2(2 \cdot 9) \\
10 \cdot 7(2 \cdot 5)\end{array}$ & $\begin{array}{c}94 \cdot 0(15 \cdot 0) \\
9 \cdot 5(2 \cdot 9) \\
8 \cdot 8(2 \cdot 4) \\
9 \cdot 0(3 \cdot 7)\end{array}$ & $\begin{array}{c}95 \cdot 0(15 \cdot 8) \\
9 \cdot 6(3 \cdot 2) \\
9 \cdot 1(2 \cdot 6) \\
9 \cdot 1(3 \cdot 3)\end{array}$ & Gender & $4 \cdot 0$ & 0.049 \\
\hline Mazes† & $10 \cdot 8(3 \cdot 1)$ & $10 \cdot 4(2 \cdot 7)$ & $10 \cdot 1(2 \cdot 6)$ & $10.8(3.5)$ & $12 \cdot 0(3 \cdot 2)$ & & & \\
\hline
\end{tabular}

IQ and factor scores in column one significantly different from the adjusted hypothetical mean (105) are highlighted in bold. Scores with an asterisk are also significantly different from 100 . Subtest scores in bold are significantly different from the expected mean of 10 . $\nmid$ Not used to calculate IQ or factor scores.

organisation $(t=0.27)$ failed to reach significance.

Four out of the 12 subtest scores were significantly lower than the hypothetical mean of $10(p<0.01)$. All four subtests are part of the verbal scale; two of these subtests are components of the verbal comprehension factor score (information: mean $=8.37, t=6.03$ and comprehension: mean $=8.95, t=4 \cdot 2$ ) and the two others contribute to the freedom from distractibility factor (arithmetic: mean $=8.9$, $t=3 \cdot 3$ and digit span: mean $=8 \cdot 75, t=4 \cdot 46$ ).

\section{(2) MANOVA}

Results of this analysis indicated a significant main effect of sex on verbal IQ $(F=4 \cdot 5$, df 1,$78 ; p=0.037$ ), and on three out of the six verbal subtests (vocabulary: $F=4 \cdot 4$, $\mathrm{df}$ 1,78, $\mathrm{p}=0.04$; comprehension: $\mathrm{F}=4.2$, df $1,78, \mathrm{p}=0.043$; arithmetic: $\mathrm{F}=4.00$, df 1,78 , $\mathrm{p}=0.049$ ). In addition, there was a significant main effect of age at treatment on the factor based index score of perceptual organisation $(F=5 \cdot 2$, df $1,77, p=0.026)$, on the similarities subtest of the verbal scale $(F=9.93$, df $1,78, p=0.002)$ and on two out of the six subtests of the performance scale (block design: $F=6.9$, df 1,78, $p=0.010$; object assembly: $F=5 \cdot 21$, df 1,77 , $p=0.025)$. The interaction of sex by age at treatment was not significant.

Elapsed time from treatment to test has been shown to be related to final cognitive outcome in some studies. ${ }^{18} 19$ Intrathecal methotrexate is also implicated in adverse cognitive outcome. ${ }^{3031}$ In the present study, however, neither covariate was significantly correlated with any of the IQs, the factor based index scores, or the subtests of the verbal and performance scales (table 2).

\section{(3) MULTIPLE REGRESSION ANALYSES}

To take full advantage of all the variance in the age at treatment variable, a series of multiple regression analyses were carried out using each of the IQ related measures as dependent variable. Table 3 shows the results of the analyses for IQ and the three factor based index scores. Both sex and age at treatment influence verbal IQ (sex: $r=0.55, \mathrm{p}=0.009$; age: $r=0.28$, $\mathrm{p}=0.019$ ) and verbal comprehension (sex: $r=0.48, \mathrm{p}=0.026$; age: $r=0.27, \mathrm{p}=0.023$ ). The significant relationship between age at treatment and perceptual organisation is confirmed $(r=0.37, \mathrm{p}=0.003)$, and, in addition, performance IQ is predicted by both age at treatment and the interaction of sex by age at treatment (age: $r=0.29, \mathrm{p}=0.02$; sex by age: $r=-0.45, \mathrm{p}=0.04)$.

Table 4 shows the significant correlations between subtest scores and the independent variables. Sex predicted the vocabulary subtest score $(r=0.51, \mathrm{p}=0.017)$ whereas age at treatment was a significant predictor of the similarities $(r=0.39, \mathrm{p}=0.0015)$ and block design $(r=0.31, p=0.013)$ subtest scores. Sex and age at treatment influenced the scores on both the object assembly (sex: $r=0.47, \mathrm{p}=0.026$; age: $r=0.38, \quad \mathrm{p}=0.0018$ ) and arithmetic (sex: $r=0.51, \quad \mathrm{p}=0.017$; age: $r=0.23, \mathrm{p}=0.05)$ subtests. Scores on object assembly were additionally correlated with the interaction

Table 3 Standardised beta values (and $p$ values) for forced multiple regression equations on IQ and factor based index scores; significant values highlighted in bold

\begin{tabular}{|c|c|c|c|c|c|}
\hline . & $\begin{array}{l}\text { Elapsed time } \\
\text { since } \\
\text { treatment }\end{array}$ & $\begin{array}{l}\text { No of } \\
\text { methotrexate } \\
\text { injections }\end{array}$ & Sex & $\begin{array}{l}\text { Age at } \\
\text { treatment }\end{array}$ & $\begin{array}{l}\text { Sex by } \\
\text { age at } \\
\text { treatment }\end{array}$ \\
\hline $\begin{array}{l}\text { Verbal IQ } \\
\text { Performance IQ } \\
\text { Verbal comprehension } \\
\text { Perceptual organisation } \\
\text { Freedom from distractibility }\end{array}$ & $\begin{array}{l}-0.06(0.57) \\
-0.05(0.64) \\
-0.08(0.42) \\
0.06(0.55) \\
0.003(0.98)\end{array}$ & $\begin{array}{c}0.015(0.89) \\
-0.05(0.63) \\
0.04(0.76) \\
-0.07(0.50) \\
-0.14(0.21)\end{array}$ & $\begin{array}{l}0.55(0.009) \\
0.34(0 \cdot 10) \\
0.48(0.026) \\
0.25(0.23) \\
0 \cdot 19(0.38)\end{array}$ & $\begin{array}{l}0.28(0.019) \\
0.29(0.02) \\
0.27(0.023) \\
0.37(0.003) \\
0.16(0.21)\end{array}$ & $\begin{array}{l}-0.36(0.009) \\
-0.45(0.04) \\
-0.30(0.16) \\
-0.32(0.13) \\
-0.15(0.50)\end{array}$ \\
\hline
\end{tabular}


Table 4 Standardised beta values (and $p$ values) for forced multiple regression equations on IQ subtest scores; significant values highlighted in bold

\begin{tabular}{|c|c|c|c|c|c|}
\hline IQ Subtests & $\begin{array}{l}\text { Elapsed time } \\
\text { since } \\
\text { treatment }\end{array}$ & $\begin{array}{l}\text { No of } \\
\text { methotrexate } \\
\text { injections }\end{array}$ & Sex & $\begin{array}{l}\text { Age at } \\
\text { treatment }\end{array}$ & $\begin{array}{l}\text { Sex by } \\
\text { age at } \\
\text { treatment }\end{array}$ \\
\hline $\begin{array}{l}\text { Similarities } \\
\text { Vocabulary } \\
\text { Block design } \\
\text { Object assembly } \\
\text { Arithmetic }\end{array}$ & $\begin{array}{c}0.007(0.94) \\
-0.16(0.13) \\
0.05(0.64) \\
0.08(0.47) \\
0.06(0.58)\end{array}$ & $\begin{array}{r}0.044(0.69) \\
-0.032(0.78) \\
-0.05(0.64) \\
-0.07(0.53) \\
-0.03(0.75)\end{array}$ & $\begin{array}{l}0.26(0.21) \\
0.51(0.017) \\
0.24(0.26) \\
0.47(0.026) \\
0.51(0.017)\end{array}$ & $\begin{array}{l}0.39(0.0015) \\
0.09(0.45) \\
0.31(0.013) \\
0.38(0.0018) \\
0.23(0.05)\end{array}$ & $\begin{array}{r}-0.19(0.37) \\
0.30(0.17) \\
-0.29(0.17) \\
-0.52(0.016) \\
-0.32(0.13)\end{array}$ \\
\hline
\end{tabular}

between sex and age at treatment $(r=-0.052$, $\mathrm{p}=0 \cdot 016)$.

\section{Discussion}

The results of this study confirm and extend previous reports of reductions in intellectual ability after presymptomatic cranial radiotherapy. ${ }^{32-34}$ Examination of the individual subtests, which contribute to global IQ, indicate that specific aspects of intellectual function are affected by treatment. Outcome was often determined both by the sex of the patient and the age at which treatment is given, but not by elapsed time since treatment.

Both girls and boys show reductions in subtests that require attention, short term verbal memory, and concentration. ${ }^{35}$ Likewise regardless of sex, abstract verbal reasoning skills were significantly correlated with age at treatment. However, age at treatment has its greatest influence on non-verbal ability. Sex exerted its effects most strongly on verbal skills, with girls showing selective impairment of verbal IQ. Also, girls treated before 4 years of age showed greater deficit than girls treated at a later stage. In the normal population there is a tendency for girls to perform better on verbal tasks than boys. The reduction in verbal ability which follows treatment suggests that the developmental mechanism that contributes to superior female verbal ability is particularly vulnerable to cranial irradiation. Boys may have a less efficient developmental mechanism for this ability but one which is more robust in response to irradiation.

The low scores on the arithmetic, digit span, and information subtests reflect diffuse reductions in short term verbal information processing. Low scores in these three subtests are often reported in children with a history of both general and specific developmental learning difficulties. ${ }^{36}$ This general information processing problem, coupled with abstract reasoning difficulties, may be a major contribution to the difficulties long term survivors are reported to have in school based attainments tasks.

Another current issue is the separate roles of cranial radiotherapy and intrathecal methotrexate in the production of deficits in neuropsychological outcome. While some authors suggest that deficits are exacerbated by methotrexate, ${ }^{37}$ it is not clear whether this interaction is additive or synergistic. ${ }^{20}$ In our relatively homogeneous sample the amount of cranial radiotherapy was held constant, with the younger children having more methotrexate injections than the six to eight given on the main protocol for children over 2 years of age at diagnosis. The relationship between age at treatment and the number of methotrexate injections is certainly a significant one and a possible confounding factor. However, the multiple regression analysis indicates that the two variables are not co-linear and supports the view that it is age at treatment which is the critical factor and not the number of methotrexate injections per se. This conclusion is consistent with the results of a study of children who had received both additional cranial radiotherapy and methotrexate after relapse. Despite total methotrexate doses 3-4 times more than that given in the current study to achieve first remission, only time between first and second treatment, age at relapse, and total radiotherapy dose predicted outcome. ${ }^{38}$

There are no data for pretreatment ability levels in this sample. However, studies have consistently shown normal ability levels at diagnosis. ${ }^{39}$ The large sample size and use of all, rather than a few, of the IQ subtests in comparison with previous reports, ${ }^{16} 17$ have re-emphasised the significant contribution of treatment at an early age to cognitive impairment and have confirmed that girls are more vulnerable than boys. The finding of differential effects of sex and age at treatment on certain aspects of intellectual ability suggests that the use of only one or two subtests to prorate IQ scores may lead to very different conclusions depending on the subtests selected. The results also emphasise the need for careful monitoring of various aspects of children's intellectual ability in as much as more global measures may fail to detect specific impairments which underlie learning difficulties. Further work on the relationship between memory, language, higher order processing ability, and intellectual ability is currently being analysed (D Christie et al; in preparation). It is critical that the relationship between intellectual difficulties and underlying neuropsychological mechanisms is examined in detail in this population to clarify the relationship between the structural and functional deficits which follow treatment for leukaemia.

The identification of risk factors for poor cognitive outcome and description of a unique pattern of impairment confirm the need for regular follow up and screening of children who receive cranial radiotherapy as part of the treatment for leukaemia. Particular attention should be paid to the development of concentration, attention, short term memory, and abstract reasoning ability in all children, whereas the development of verbal processing skills need greater attention in girls.

We thank Dr Elizabeth B Isaacs for help and advice and Dr Jim Stevenson for suggestions regarding data analysis.

1 Aur RJA, Simone J, Hustu HO, et al. Central nervous system therapy and combination chemotherapy of child2 Ponchedly C. Prophylactic CNS therapy in childhood acute leukaemia. Review of methods used. Am $\mathcal{F}$ Pediatr Hematol Oncol 1979; 1: 119-26.

3 Chessells JM, Bailey CC, Richards S. MRC UKALL X. The UK protocol for childhood ALL: 1985-1990. The Medical Research Council working party on childhood 4 Shalet SM. Irradiation-induced growth failure. Clinical .

5 Leiper AD, Stanhope R, Kitching P, Chessells JM. Precocious and premature puberty associated with treatment of acute lymphoblastic leukaemia. Arch Dis Child
1987; 62: 1107-12. 
6 Peylan-Ramu N, Poplack DG, Pizzo PA, Adornato BT, DiChiro G. Abnormal CT scans of the brain in asymptomatic children with acute lymphocytic leukaemia afte prophylactic treatment of the central nervous system with radiation and intrathecal chemotherapy. $N$ Engl f Med 1978; 298: 815-9.

7 Wilson DA, Nitschke R, Bowman ME, Chaffin MJ, Sexaue CL, Prince JR. Transient white matter changes on MRI images in children undergoing chemotherapy for acute lymphoblastic leukaemia: correlations with neuropsychologic deficiencies. Radiology 1991; 180: 205-9.

8 Poplack DG, Brouwers P. Adverse sequelae of central nervous system. Clinics in Oncology 1985; 4: 263-85.

9 Brouwers P, Riccardi R, Poplack DG, Fedio P. Attentional deficits in long term survivors of childhood acute Neuropsychology 1984; 6: 325-36.

10 Fletcher JM, Copeland DR. Neurobehavioural effects of central nervous system prophylactic treatment of cancer in children. I Clin Exp Neuropsychol 1988; 10: 495-538.

11 Price RA, Jamieson PA. The central nervous system in childhood leukaemia II. Subacute leukoencephalopathy. Cancer 1975; 35: 306-18.

12 Gangji D, Reaman GH, Cohen SR, Bleyer WA, Poplack DG. Leukoencephalopathy and elevated levels of myelin basic protein in the cerebrospinal fluid of patients with acute lymphoblastic leukaemia. $N$ Engl f Med 1980; 303: 19-21.

13 Leiper AD, Chessells JM. Acute lymphoblastic leukaemia under 2 years. Arch Dis Child 1986; 61: 1007-12.

14 Kinney HC, Brody BA, Kloman AS, Gilles FH. Sequence of central nervous system myelination in human infancy. II. Patterns of myelination in autopsied infants. f Neuropathol Exp Neurol 1988; 47: 217-34.

15 Uruena M, Stanhope R, Chessells JM, Leiper AD. Impaired pubertal growth in acute lymphoblastic leukaemia. Arch Dis Child 1991; 66: 1403-7.

16 Robison LL, Nesbit ME, Sather HN, Meadows AT, Ortega JA, Hammond GD. Factors associated with IQ scores in long term survivors of childhood acute lymphoblastic leukaemia. Am $\mathcal{F}$ Pediatr Hematol Oncol 1984; 6: 115-21.

17 Waber DP, Tarbell NJ, Kahn CM, Gelber RD, Sallan SE. The relationship of sex and treatment modality to neuropsychologic outcome in childhood acute neuropsychologic outcome in childhood acute 18 Cousens P, Waters B, Said J, Stevens M. Cognitive effects of cranial irradiation in leukaemia: a survey and metaof cranial irradiation in leukaemia: a survey and m
analysis. $\mathcal{F}$ Child Psychol Psychiatry 1988; 29: 839-52.

19 Mulhern RK, Kovnar E, Langston J, et al. Long term survivors of leukaemia treated in infancy: factors associated with neuropsychologic status. $\mathcal{f}$ Clin Oncol 1992; 10 1095-102.

20 Dowell RE, Copeland DR, Francis DJ, Fletcher JM, Stoval $M$. Absence of synergistic effects of CNS treatments on neuropsychologic test performance among children. $f \mathrm{Clin}$ Oncol 1991; 9: 1029-36.

21 Chessells JM, Leiper AD, Tiedermann $\mathrm{K}$, Hardisty RM, Richards S. Oral methotrexate is as effective as intramuscular in continuing maintenance therapy of acute muscular in continuing maintenance therapy of acute

22 Pinkerton CR, Bowman A, Holtzel H, Chessells JM. Intensive consolidation therapy for acute lymphoblastic leukaem
(UKALL X pilot study). Arch Dis Child 1987; 62: 12-8.

23 Wechsler D. Wechsler intelligence scale for children - revised UK edition. Berkshire: NFER Nelson, 1982.

24 Wechsler D. Wechsler adult intelligence scale - revised UK edition. Kent: Psychological Corporation, 1986.

25 Wechsler D. Preschool and primary scale of intelligence revised. Kent: Psychological Corporation, 1990.

26 Gutkin TB. The WISC-R verbal comprehension, perceptual organisation and freedom from distractibility quotients: data for practitioners. Psychology in the Schools 1979; 16: 356-60.

27 Flynn J. The mean IQ of Americans: massive gains 1932 to 1978. Psychol Bull 1984; 95: 29-51.

28 Flynn J. Massive IQ gains in 14 nations: what IQ tests really measure. Psychol Bull 1987; 101: 171-91.

29 Fuggle PW, Tokar S, Grant DB, Smith I. Rising IQ scores in British children: recent evidence. $\mathcal{f}$ Child Psychol Psychiatry 1992; 33: 1241-7.

30 Giralt J, Ortega JA, Olive T, Verges R, Forio I, Salvador L. Long-term neuropsychologic sequelae of childhood leukaemia: comparison of two CNS prophylactic regimens. Int 7 Radiat Oncol Biol Phys 1992; 24: 49-53.

31 Brown RT, Madan-Swain A, Pais R, Lambert RG, Sexson S, Ragab A. Chemotherapy for acute lymphocytic leukaemia: cognitive and academic sequelae. $\mathcal{f}$ Pediat 1992; 121: 885-9.

32 Copeland DR, Dowell RE, Fletcher JM, et al. Neuropsychological effects of childhood cancer treatment. F Child Neurol 1988; 3: 53-62.

33 Brouwers P. Neuropsychological abilities of long term survivors of childhood leukaemia. In: Aaronson NK, Beckman J, eds. The quality of life of cancer patients. New Yeckman J, eds. The quality of life of

34 Moss H, Nannis ED, Poplack DG. The effects of prophylactic treatment of the central nervous system on the intellectual functioning of children with acute lymphoblastic lectual functioning of children with acute

35 Brouwers P, Poplack DG. Memory and learning sequelae in long-term survivors of acute lymphoblastic leukaemia association with attention deficits. Am $\mathcal{F}$ Pediatr Hemato Oncol 1990; 12: 174-81.

36 Rugel RP. WISC subtest scores of disabled readers: a review with respect to Bannatyne's categorization. Fournal of Learning Disabilities 1974; 17: 48-5

37 Ochs J, Mulhern RK. Late effects of antileukaemic treatment. Pediatr Clin North Am 1988; 35: 815-33.

38 Christie D, Battin M, Leiper AD, Chessells JM Vargha-Khadem F, Neville B. Neuropsychological and neurological outcome after relapse of lymphoblastic leukaemia. Arch Dis Child 1994; 70: 275-80.

39 Rubenstein CL, Varni JW, Katz ER. Cognitive functioning in long-term survivors of childhood leukaemia: a prospective analysis. $\mathcal{F}$ Dev Behav Pediatr 1990; 11: 301-5.

\section{Appendix}

For all children the verbal IQ is calculated from five subtests: information, similarities, vocabulary, comprehension, and arithmetic. Performance IQ is calculated from five subtests (for the WISC-R and WAIS-R): picture completion, picture arrangement, block design, object assembly, and coding. In the WPPSI-R picture arrangement and coding are replaced with two paper and pencil tests, mazes and geometric designs, therefore perceptual organisation and freedom from distractibility cannot be calculated for this scale.

Verbal comprehension provides an indication of how a child reasons verbally and how well he or she acquires and uses information to establish relationships between words and concepts.

- Information: a test of the accumulation of general knowledge.

- Similarities: a test of association of ideas and unifying verbal concepts - for example, questions which ask how things are similar or alike.

- Vocabulary: explanation of meanings of words are required.

- Comprehension: comprehension of ideas, explanation of reasons, and why they are important. Quality of the answer given is taken into consideration.

Perceptual organisation indicates how a child makes sense of visual information. It also provides a measure of the ability to organise objects into space, and to establish relationships between visual components at a more abstract level.

- Picture completion: identify a missing feature in a picture.

- Picture arrangement: make a sensible picture story from a random presentation of picture cards.

- Block design: copying patterns using blocks that can be put together so as to make a design.

- Object assembly: a puzzle type test where pieces have to be put together to make an object.

Freedom from distractibility is an indicator of the child's ability to retain information in memory in the short term, to sustain attention and to maintain sufficient concentration to perform mental operations.

- Arithmetic: mental arithmetic and oral computational skills.

- Digit span: remember lists of digits presented in groups of increasing number.

- Coding: place coding marks from a specimen guide under numbers that have to be coded in a similar way to the example. It is a test of speed, visual memory, and hand/eye coordination. 